\title{
Características atribuídas a jogos educativos: uma interpretação Analítico-Comportamental
}

\author{
Mariana Gomide Panosso \\ Universidade Federal de São Carlos - São Carlos - SP \\ Silvia Regina de Souza \\ Departamento de Psicologia Geral e Análise do Comportamento da Universidade Estadual de Londrina - \\ Universidade Estadual de Londrina - Londrina - PR \\ Verônica Bender Haydu \\ Departamento de Psicologia Geral e Análise do Comportamento da Universidade Estadual de Londrina - \\ Universidade Estadual de Londrina - Londrina - PR
}

\begin{abstract}
Resumo
Há muitas maneiras de arranjar contingências para promover a aprendizagem, sendo os jogos educativos uma delas. Este artigo apresenta uma revisão da bibliografia relativa a pesquisas empíricas que empregaram jogos educativos para a coleta de dados com o objetivo de identificar argumentos em que os autores especificam as características dos jogos e interpretá-las com base nos princípios da Análise do Comportamento. Realizou-se uma busca com o operador boleano "AND" nas bases de dados Scielo e Pepsic e os descritores jogos educativos; jogos AND educação; jogos AND saúde, na Base Scielo e jogos; jogo; jogos AND brinquedos na Pepsic. Foram selecionados sete artigos e identificaram-se argumentos que permitiram destacar as seguintes características dos jogos: operações estabelecedoras, instrucional e de controle de estímulos (discriminação e generalização). Reconheceu-se a partir dos argumentos dos autores da bibliografia revisada que os jogos educativos apresentam características de estratégias de ensino e motivadoras e podem contribuir para a programação de contingências de ensino eficazes e eficientes.
\end{abstract}

Palavras-chave: Análise do Comportamento; jogos educativos; aprendizagem.

\section{Characteristics attributed to educational games: an interpretation behavior analytic}

\begin{abstract}
The bibliography of empirical research that used educational games for the data collection has been reviewed in order to identify arguments in which authors specified the games characteristics and interpret these based on the principles of Behavior Analysis. A search with the boolean operator "AND" has been performed in the databases Scielo and Pepsic and the descriptors educational games, games AND education, games AND health (Base Scielo) and games; game; games AND toys (Pepsic). Seven articles were selected and the arguments that have underlined the following games have been identified: establishing operations, instructional and stimulus control (discrimination and generalization). It was recognized from the authors' arguments of the reviewed literature that educational games have characteristics of teaching strategies and motivating, leading to the conclusion that they can contribute to the programming of effective and efficient teaching.
\end{abstract}

Keywords: Behavior Analysis; educational games; learning.

\section{Características atribuidas a juegos educativos: una interpretación Analítico- Comportamental}

\section{Resumen}

Hay muchos modos de conseguir contingencias para promover el aprendizaje, siendo los juegos educativos una de ellas. Este artículo presenta una revisión de la bibliografía relativa a la investigación empíricas que emplearon juegos educativos para la recolecta de datos con el objetivo de identificar argumentos en que los autores especifican las características de los juegos e interpretarlas con base en los principios del Análisis del Comportamiento. Se realizó una búsqueda con el operador boleano "AND" en las bases de datos Scielo y Pepsic y los descriptores juegos educativos; jugos AND educación; juegos AND salud, en la Base Scielo y juegos; juego; juegos AND juguetes en la Pepsic. Fueron seleccionados siete artículos y se identificaron argumentos que permitieron destacar las siguientes características de los juegos: operaciones establecedoras, instruccional y de control de estímulos (discriminación y generalización). Se reconoció a partir de los argumentos de los autores de la bibliografía revisada que los juegos educativos presentan características de estrategias de enseñanza motivadoras y pueden contribuir para la programación de contingencias de enseñanza eficaces y eficientes.

Palabras-clave: Análisis del Comportamiento; juegos educativos; aprendizaje. 


\section{Introdução}

No contexto educacional é importante promover contingências que facilitem e que possibilitem acelerar o processo de aprendizagem e que também proporcionem situações para que comportamentos específicos sejam emitidos, conforme sugeriu Skinner (1968/1972). Assim, pode-se afirmar que não é apropriado esperar que o aprendiz se comporte de uma determinada maneira para só então apresentar consequências que venham a fortalecer esse comportamento. De acordo com Skinner (1968/1972, p.62) ensinar é arranjar "contingências de reforço sob as quais o aluno aprende", portanto "quem é ensinado aprende mais rapidamente do que quem não é” (Skinner 1968/1972, p.4).

Diversos aspectos devem ser considerados quando se aborda a questão do planejamento do ensino. Por exemplo, deve-se especificar claramente o que ensinar; o ensino deve ser apropriado para o aprendiz; a razão para aquele ensino deve estar clara e, também, a forma de ensinar deve ser planejada. Esse último aspecto envolve determinar o modo pelo qual as contingências de ensino são arranjadas.

Há muitas maneiras de arranjar contingências para promover a aprendizagem, sendo os jogos educativos uma delas. Segundo Dondi e Moretti (2007), os jogos educativos são definidos como aqueles que possuem um objetivo didático explícito e podem ser adotados ou adaptados para melhorar, apoiar ou promover os processos de aprendizagem em um contexto de aprendizagem formal ou informal. Além disso, esses autores consideram que os jogos possuem regras e possibilitam o entretenimento, devendo, portanto, como qualquer outro recurso didático e metodológico, possuir objetivos definidos, coerência nas estratégias utilizadas e favorecer o alcance dos objetivos de aprendizagem. Devido a esses aspectos, os jogos têm sido objeto de estudo de pesquisadores de diferentes áreas, como da Saúde, da Educação, da Biologia, da Psicologia dentre outros (por exemplo, Canto, \& Zacarias, 2009; Cezar, Morais, Calsa, \& Romualdo, 2008; Fonseca, Scochi, \& Mello, 2002; Toscani, \& cols., 2007).

Ao se considerar os estudos realizados por pesquisadores de áreas como da Saúde, da Educação, da Biologia, podem ser destacados os seguintes jogos: (a) área da Saúde - jogo para o ensino de prevenção de doenças parasitológicas (Toscani, \& cols., 2007) e jogo para o ensino de puérperas sobre conhecimentos relacionados à saúde (Fonseca, \& cols., 2002); (b) área da Biologia - jogo voltado para o ensino de biomas brasileiros (Canto, \& Zacarias, 2009); (c) área da Educação - jogo para o ensino de acentuação (Cezar, \& cols., 2008). Os autores desses jogos/estudos e de outros da bibliografia dessas áreas têm atribuído aos jogos as mais diferentes características educacionais, entre elas, a de serem estratégias motivadoras a serem usadas no ensino de conteúdos (Canto, \& Zacarias, 2009), a de serem usados como recurso que favorece a tomada de consciência por parte dos alunos (Cezar, \& cols., 2008) e a de permitirem a tomada de decisão (Fonseca, \& cols., 2002). Outro aspecto destacado pelos pesquisadores relaciona-se à importância dos jogos como um recurso necessário para fornecer aos aprendizes um ambiente apropriado e diversificado para o aprendizado de habilidades específicas.

Analistas do comportamento também têm desenvolvido e avaliado jogos educativos como para o ensino de princípios/conceitos da Análise Experimental do Comportamento para adultos e jovens (Ferreira, \& cols., 2012; Haydu, 2014); para o ensino de habilidades acadêmicas, utilizando o modelo da equivalência de estímulos, como a leitura e a escrita (Siqueira, Barros, Marques, \& Monteiro, 2011; Souza, \& Hübner, 2010); para o manejo de dinheiro (Sdoukos, \& cols., 2010). Além desses, foram desenvolvidos jogos usados em intervenções terapêuticas, podendo ser citados os jogos "Será Que Conheço Você?" (Moura, 2006) e o "Baralho das Emoções" (Caminha, \& Caminha, 2010), que apesar de ter um caráter clínico, não deixam de ter características educacionais. Nos estudos relatados por analistas do comportamento, foram feitas análises funcionais específicas das relações comportamentais estabelecidas pelo jogo, podendo-se afirmar que ele é um recurso que permite o estabelecimento de diversas contingências que favorecem o processo de aprendizagem (Ferreira, \& cols., 2012; Haydu, 2014; Siqueira, Barros, Marques, \& Monteiro, 2011; Souza, \& Hübner, 2010; Xander, 2013).

Visto que os jogos educativos são considerados instrumentos por meio dos quais contingências de ensino podem ser arranjadas a fim de promover a aprendizagem, este estudo revisou a bibliografia de pesquisas empíricas que empregaram jogos educativos na coleta de dados, com o objetivo de identificar argumentos em que os autores especificaram as características dos jogos e posteriormente interpretá-los com base nos princípios da Análise do Comportamento, para identificar os processos comportamentais subjacentes aos jogos. A condição de se fazer interpretações analíticas comportamentais das características dos jogos determinou que este estudo se limitasse à análise de pesquisas empíricas.

\section{Método}

A busca por artigos científicos sobre os jogos educativos foi realizada nas bases de dados Scielo e Pepsic, desde a criação das bases até julho de 2013. Na pesquisa bibliográfica preliminar (Fase 1) foram introduzidos os seguintes descritores para a busca com o operador booleano "AND": jogos; jogo; jogos AND brinquedos. Devido ao grande número de artigos encontrados inicialmente na base de dados Scielo (912 artigos), a busca nesta base foi refinada utilizando os seguintes descritores: jogos educativos, jogos AND educação e jogos AND saúde e foram encontrados 256 artigos. Na base de dados Pepsic foram encontrados 76 artigos com os descritores inicialmente especificados (jogos; jogo; jogos AND brinquedos). A busca nesta base de dados não foi refinada conforme foi feito com os resultados da busca no Scielo devido ao número relativamente reduzido de artigos encontrados com esses descritores. Um total de 332 artigos foi selecionado para realizar a leitura dos resumos. Em seguida, realizou-se a pesquisa bibliográfica manual 
(Fase 2), com a leitura de todos os títulos e resumos dos 332 artigos selecionados na Fase 1.

Na revisão crítica dos artigos (Fase 3), selecionaram-se os artigos que relatavam pesquisas empíricas que utilizaram jogos educativos no procedimento e nas quais foram feitas referências ao tema "jogos educativos" e excluíram-se artigos que faziam referência a jogos esportivos, jogos coorporativos, jogos eletrônicos, jogos sociodramáticos e jogo patológico. A aplicação desses critérios de exclusão levou à seleção de sete artigos. Após a leitura dos resumos e a seleção dos artigos, procedeu-se à leitura dos artigos. Em seguida, realizou-se uma seleção dos argumentos em que os autores especificam as características educativas dos jogos (Fase 4). Os argumentos não tinham que ser redigidos em linguagem analítico-comportamental, mas foram interpretados com base nos princípios e conceitos da Análise do Comportamento, sendo esses princípios e conceitos descritos e analisados no contexto dos jogos. Esses dados são apresentados na próxima seção do presente estudo, caracterizando os resultados do mesmo.

\section{Resultados e Discussão}

Os resultados numéricos da consulta às bases de dados Scielo e Pepsic, as palavras-chave por meio das quais foram selecionados os artigos de interesse para os objetivos desta revisão, o número de artigos encontrados e o número de artigos recuperados e utilizados para análise encontram-se na Tabela 1.

Os sete artigos selecionados descrevem o uso dos jogos como recursos educacionais e especificam as suas características. Nesses artigos, os jogos foram estudados por pesquisadores de diferentes áreas do conhecimento, o que foi constatado pela identificação da formação dos autores (Medicina, Enfermagem, Pedagogia, Psicologia e Letras). A Tabela 2 apresenta as referências das publicações, bem como o título e o objetivo dos estudos da revisão.

Após a leitura na íntegra dos artigos selecionados, foram identificadas e reproduzidas sentenças em que o(s) autor(es) apresentam argumentos referentes às características atribuídas por eles aos jogos usados em seus estudos. Essas sentenças/argumentos, retiradas das seções de resultados e discussão, foram interpretadas com base nos princípios da Análise do Comportamento.

As seguintes sentenças/argumentos descrevem os jogos como tendo a característica motivadora. Foram sublinhadas as partes das sentenças em que os autores identificam essa função nos jogos usados por eles em suas pesquisas.

(...) é possível supor que o jogo tenha criado um ambiente motivador (Santos, \& Ortega, 2009, p.46);

O jogo de regras é um instrumento que se encaixa como uma das possibilidades para o trabalho do professor seguir tais sugestões, na medida em que cria uma situação lúdica. motivadora e desafiadora, capaz de mobilizar e desenvolver aspectos cognitivos (Santos, \& Ortega, 2009, p.47);

Surgiu a ideia da aplicação do jogo Super Trunfo Árvores Brasileiras com o propósito de trabalhar este conteúdo programático de forma motivante e divertida (...) (Canto, \& Zacarias, 2009, p.152);

A oportunidade para discussão durante o jogo aumenta 0 interesse e a motivação. Facilita a assimilação de conceitos pela estimulação do processo cognitivo, permite a expressão de opiniões, esclarece conceitos, reforça e suplementa aprendizagem e promove positiva aprendizagem afetiva (Fonseca, \& cols., 2002, p.170).

Ressalta-se, ainda, o caráter motivacional dos jogos. (Souza, \& Hübner, 2010, p. 238).

(...) Observações não sistemáticas indicaram que as atividades de ensino com os jogos aumentaram a probabilidade de as crianças se envolverem nas tarefas e aprenderem o que estava sendo ensinado. (Sudo, Soares, Souza, \& Haydu, 2008, p. 235)

Tabela 1. Bases de dados consultadas, descritores e número de artigos encontrados e recuperados a partir da busca.

\begin{tabular}{llcc}
\hline \multicolumn{1}{c}{ Base de Dados } & \multicolumn{1}{c}{ Palavras-chave } & $N^{\circ}$ de artigos encontrados & Artigos recuperados \\
\hline \multirow{3}{*}{ Scielo } & jogos educativos & 14 & 0 \\
\cline { 2 - 4 } & jogos AND educação & 158 & 2 \\
\cline { 2 - 4 } & jogos AND saúde & 84 & 0 \\
\hline Pepsic & jogos & 32 & 1 \\
\cline { 2 - 4 } & jogo & 35 & 3 \\
\cline { 2 - 4 } & jogos AND brinquedos & 09 & 1 \\
\hline
\end{tabular}


Tabela 2. Referência, título e objetivos dos estudos selecionados para análise

\begin{tabular}{|c|c|c|c|}
\hline Referências & Títulos & Objetivos dos estudos & $\begin{array}{l}\text { Princípios e conceitos } \\
\qquad \text { da AC }\end{array}$ \\
\hline $\begin{array}{l}\text { Cezar, Morais, } \\
\text { Calsa, \& } \\
\text { Romualdo (2008) }\end{array}$ & $\begin{array}{l}\text { Acentuação gráfica: criação } \\
\text { e aplicação de um jogo de } \\
\text { regras. }\end{array}$ & $\begin{array}{l}\text { Apresentar os resultados da } \\
\text { criação e aplicação de um jogo de } \\
\text { regras sobre acentuação gráfica } \\
\text { com alunos de } 4^{a} \text { e } 5^{a} \text { séries e } \\
\text { suas possibilidades de uso no } \\
\text { atendimento psicopedagógico. }\end{array}$ & $\begin{array}{l}\text { Reforço; Operação } \\
\text { Estabelecedora; } \\
\text { Controle por Regras; } \\
\text { Resolução de } \\
\text { Problemas }\end{array}$ \\
\hline $\begin{array}{l}\text { Canto, \& } \\
\text { Zacarias (2009) }\end{array}$ & $\begin{array}{l}\text { Utilização do jogo Super } \\
\text { Trunfo Árvores Brasileiras } \\
\text { como instrumento facilitador } \\
\text { no ensino dos biomas } \\
\text { brasileiros }\end{array}$ & $\begin{array}{l}\text { Analisar a funcionalidade do jogo } \\
\text { Super Trunfo Árvores Brasileiras } \\
\text { como instrumento pedagógico para } \\
\text { o ensino dos biomas brasileiros. }\end{array}$ & $\begin{array}{l}\text { Operação } \\
\text { Estabelecedora }\end{array}$ \\
\hline $\begin{array}{l}\text { Santos, \& Ortega } \\
\text { (2009) }\end{array}$ & $\begin{array}{l}\text { O jogo de regras como } \\
\text { recurso para avaliação } \\
\text { e intervenção: um } \\
\text { estudo piagetiano com } \\
\text { adolescentes. }\end{array}$ & $\begin{array}{l}\text { Caracterizar o nível de } \\
\text { compreensão de um jogo de } \\
\text { regras em adolescentes do sexo } \\
\text { feminino. }\end{array}$ & $\begin{array}{l}\text { Operação } \\
\text { Estabelecedora; } \\
\text { Reforço; Generalização } \\
\text { de Estímulos; Controle } \\
\text { por Regras; Resolução } \\
\text { de Problemas }\end{array}$ \\
\hline $\begin{array}{l}\text { Fonseca, Scochi, } \\
\text { \& Mello (2002) }\end{array}$ & $\begin{array}{l}\text { A educação em saúde de } \\
\text { puérpereas em alojamento } \\
\text { conjunto neonatal: aquisição } \\
\text { de conhecimento mediado } \\
\text { pelo uso de um jogo } \\
\text { educativo. }\end{array}$ & $\begin{array}{l}\text { Verificar a aquisição de } \\
\text { conhecimento nas atividades de } \\
\text { educação em saúde, mediada pela } \\
\text { utilização de um jogo educativo } \\
\text { sobre aleitamento materno e } \\
\text { cuidados básicos com o recém- } \\
\text { nascido, em alojamento conjunto. }\end{array}$ & $\begin{array}{l}\text { Operação } \\
\text { Estabelecedora; } \\
\text { Reforço; Controle por } \\
\text { Regras }\end{array}$ \\
\hline $\begin{array}{l}\text { Souza, \& Hübner } \\
\text { (2010) }\end{array}$ & $\begin{array}{l}\text { Efeitos de um jogo de } \\
\text { tabuleiro educativo na } \\
\text { aquisição de leitura e escrita. }\end{array}$ & $\begin{array}{l}\text { Investigar se crianças não } \\
\text { alfabetizadas aprenderiam as } \\
\text { relações entre palavra falada, } \\
\text { figura, palavra impressa e escrita } \\
\text { manuscrita por meio do jogo de } \\
\text { tabuleiro Abrakedabra. }\end{array}$ & $\begin{array}{l}\text { O p e r a ç ã o } \\
\text { Estabelecedora; } \\
\text { Reforço }\end{array}$ \\
\hline $\begin{array}{l}\text { Sudo, Soares, } \\
\text { Souza, \& Haydu } \\
(2008)\end{array}$ & $\begin{array}{l}\text { Equivalência de estímulos e } \\
\text { uso de jogos para ensinar } \\
\text { leitura e escrita. }\end{array}$ & $\begin{array}{l}\text { Investigar se crianças que } \\
\text { apresentavam erros de escrita de } \\
\text { dissílabos simples aprenderiam } \\
\text { a escrever corretamente por } \\
\text { meio de jogos que ensinassem } \\
\text { diferentes relações. }\end{array}$ & $\begin{array}{l}\text { O p e r a ç ã o } \\
\text { Es t a b e l e c e d o ra; } \\
\text { Generalização de } \\
\text { Estímulos, Resolução } \\
\text { de Problemas }\end{array}$ \\
\hline $\begin{array}{l}\text { Toscani, \& cols. } \\
\text { (2007) }\end{array}$ & $\begin{array}{l}\text { Desenvolvimento } \\
\text { análise de jogo educativo } \\
\text { para crianças visando à } \\
\text { prevenção de doenças } \\
\text { parasitológicas. }\end{array}$ & $\begin{array}{l}\text { Avaliar o uso do jogo de tabuleiro } \\
\text { como estratégia educativa aplicado } \\
\text { na aprendizagem de medidas } \\
\text { profiláticas nas parasitoses } \\
\text { intestinais em escolares de } 7 \text { a } 13 \\
\text { anos. }\end{array}$ & $\begin{array}{l}\text { Resolução } \\
\text { Problemas }\end{array}$ \\
\hline
\end{tabular}

Observa-se nos argumentos selecionados que os autores atribuem aos jogos a característica motivadora devido à capacidade "de mobilizar" os jogadores (Santos, \& Ortega, 2009, p. 47). O jogo é evidenciado como aquele que promove "a oportunidade para discussão" (Fonseca, \& cols., 2002, p.170), levando a um aumento da motivação.
As situações de aprendizagem arranjadas pelo jogo podem estabelecer relações entre eventos, auxiliando o jogador a emitir respostas apropriadas ao conteúdo que o jogo se propõe a ensinar, produzindo consequências que podem ser identificadas como reforçadoras. 
Jogos e brinquedos, de acordo com Skinner (1968/1972), possuem consequências naturalmente reforçadoras, com os quais muitas vezes as crianças brincam por horas, pois eles informam à criança sobre as modificações que ela pode provocar no ambiente. Esse controle da natureza, conforme descrito por Skinner, embora tênue, é em si mesmo reforçador. O reforço natural é aquele que é produto direto do próprio comportamento sem haver necessidade de ganhos externos (Matos, 1993; Moreira, \& Medeiros, 2007).

No contexto do jogo, à medida que o jogador aprende respostas relacionadas ao conteúdo educativo que compõe o jogo (avançando no conhecimento, explicando aos colegas o êxito obtido), são produzidas, além dos reforçadores arbitrários (como o ganho de pontos), consequências inerentes à própria aprendizagem (reforços não arbitrários), que podem ser consideradas como sendo reforços naturais.

A presença do reforço natural já seria relevante para determinar a escolha por esse instrumento como um meio de auxílio para se programar contingências de ensino. Somado a isso, há de se considerar também que o reforço imediato das repostas corretas pode ser programado por meio de eventos reforçadores arbitrários. Os reforçadores arbitrários como produto indireto (Skinner, 1968/1972) modelam a topografia do comportamento muito antes dele poder produzir consequências naturais (Skinner, 1968/1972). Nos jogos educativos, eles podem ser programados, por exemplo, por meio de pontuação ou pelo fato de o jogador ganhar mais chances de jogar. Portanto, pode-se afirmar que, de acordo com os autores dos artigos revisados, os jogos promovem situações nas quais operações motivacionais estão envolvidas.

Para fortalecer a conclusão especificada no parágrafo anterior, buscaram-se argumentos que pudessem confirmar essa interpretação. As sentenças consideradas como argumentos de que o jogo é motivador são aquelas que identificaram uma frequência alta das respostas de jogar, as consequências reforçadoras que mantêm essas respostas e as operações que estabelecem as condições sob as quais essas consequências podem tornar-se efetivas como reforçadoras. As sentenças reproduzidas a seguir foram extraídas dos resultados e discussão das pesquisas selecionadas, sendo sublinhadas as partes que permitem identificar os efeitos reforçadores e de operações estabelecedoras, ou seja, a elevada probabilidade ou um aumento das respostas de jogar.

(...) ao ser indagado pelos colegas sobre a razão de seu inesperado e repentino êxito no jogo, AC passou a explicar ao grupo seus procedimentos (Cezar, \& cols., 2008, p.71);

(...) ganhou dez das quinze partidas no campeonato (Santos, \& Ortega, 2009, p.42);

Observou-se um interesse em adquirir o jogo (Canto, \& Zacarias, 2009, p. 150);

(...) as adolescentes pesquisadas estiveram durante todo o tempo motivadas, tendo em vista que ficavam depois do turno de aula (almoçavam na escola), não tiveram nenhuma falta e ainda disseram se precisar é só chamar (Fonseca, \& cols., 2002, p.47).

Durante o estudo não houve desistência por parte das crianças ou recusa em participar das sessões. Na verdade, observações informais mostraram que todas as crianças queriam participar das sessões e pediam (...) (Souza, \& Hübner, 2010, p. 238)

Algumas das citações anteriores permitem observar que houve uma elevada probabilidade ou um aumento das respostas de jogar após a primeira ocorrência desta resposta. Isso permite pressupor que consequências reforçadoras estão envolvidas na contingência, conforme foi argumentado anteriormente. Para o analista do comportamento, a motivação (operações estabelecedoras - Michael, 2004; Sundberg, 2013) é explicada a partir do conceito de reforço, considerando não somente a presença da consequência de uma resposta, mas sua eficácia no fortalecimento do comportamento. As operações estabelecedoras são, assim, definidas como variáveis ambientais, operações ou condições de estímulos, que alteram momentaneamente a efetividade reforçadora de outros eventos e a frequência de ocorrência de todo o comportamento que foi reforçado por esses eventos (Michael, 2004). Nos argumentos apresentados pelos autores, identificou-se que a frequência do comportamento de jogar, identificada pela descrição de que havia grande procura ou espera para jogar, faz referência ao jogo como um instrumento que possui consequências reforçadoras, entre elas ganhar os pontos.

No contexto dos jogos, os pontos podem ter sua efetividade reforçadora alterada em razão de regras como: "Quem tiver mais pontos ganha o jogo". Essa regra possibilita que comportamentos que no passado tenham produzido pontos venham a ser evocados. Isso evidencia mais um processo comportamental que é o fato de regras poderem funcionar como operações estabelecedoras que alteram a efetividade reforçadora ou punidora de estímulos como pontos, aumentando sua efetividade como reforçador ou punidor (Schlinger, \& Blakely, 1987).

\section{Jogos como estratégia de ensino}

Outra característica presente nos jogos, de acordo com os autores, refere-se ao fato de fornecerem regras tanto para a resolução de problemas como para a compreensão do próprio jogo e de conteúdos específicos, conforme apresentam os seguintes argumentos:

(...) conforme as dicas são reveladas, os sujeitos levantam hipóteses acerca da regra de acentuação gráfica da palavra em foco (Cezar, \& cols., 2008, p. 69);

(...) o jogo de regras parece permitir evolução do nível de compreensão do jogo (Santos, \& Ortega, 2009, p. 46). 
(...) a atividade educativa mediada pelo uso de um jogo contribuiu para a aquisição de conhecimento sobre amamentação e cuidados com o RN (Fonseca, \& cols., 2002, p.168)

(...) enfrentamento de situações problemas nos jogos. Tais situações obrigam os jogadores a organizar novas estratégias de ação para alcançar um resultado favorável (Cezar, \& cols., 2008, p. 71).

Foram criadas situações-problemas (Santos, \& Ortega, 2009, p. 36).

Esses argumentos sugerem que as regras ou dicas fornecidas pelo jogo podem favorecer o aprendizado do aluno, de acordo com o que o jogo se propõe a ensinar, e podem estabelecer controle instrucional, bem como a aquisição de repertório de resolução de problemas. As dicas fornecidas podem auxiliar o jogador a produzir outros estímulos discriminativos acerca da resposta que deverá ser emitida, ou seja, levantar hipóteses e emitir a resposta solução que será reforçada. Essas características dos jogos podem ser identificadas com comportamento governado por regras. Uma regra é considerada como sendo estímulo discriminativo que especifica contingências (Skinner, 1969/1980) ou como estímulos alteradores de função de outros estímulos (Schlinger, 1993). Por exemplo, a forma como os jogos Acentolândia (Cezar, \& cols., 2008) e Quoridor (Santos, \& Ortega, 2009) foram organizados, permite que se identifiquem as variáveis que evidenciam as regras como estímulos discriminativos. No primeiro, as dicas sobre a quantidade de vogais, consoantes ou sílabas que a palavra continha, a classificação da palavra (oxítona, paroxítona ou proparoxítona) ou a informação de que a palavra acentuada selecionada possuía a mesma regra de acentuação de outra palavra são elementos que podem ser identificados como regras que orientam a ação do jogador, uma vez que o comportamento deste fica sob o controle de estímulos discriminativos verbais. Além de estabelecer o seguimento de regras planejado, os jogos estabelecem contingências para o controle instrucional conforme apontado anteriormente. Por exemplo, no jogo Quoridor, as regras versavam sobre a posição das peças no tabuleiro e as possíveis consequências a depender da movimentação dessas peças. Nesse jogo, assim como na maioria dos jogos (se não todos), as instruções sobre como jogar são regras que, uma vez seguidas, aumentam a probabilidade de ganhar o jogo, o reforço mais explícito desse tipo de atividade. "Um jogo com regras especifica consequências e comportamentos que conduzem a estas consequências" (Rose, \& Gil, 2003, p. 378), caracterizando o controle instrucional e a aquisição de repertório de seguir regras.

As situações-problema apresentadas pelos jogos criam um contexto em que os jogadores emitem respostas para tentar solucioná-las. Nessa tentativa, há a manipulação de variáveis que permitem a produção de estímulos discriminativos que auxiliam o jogador a se aproximar da resposta correta e consequentemente ter suas respostas reforçadas. As variáveis que fortalecem essa interpretação podem ser identificadas na descrição de como as situações-problema são apresentadas nos jogos: as intervenções realizadas pela pesquisadora a respeito de estratégias para solucionar os problemas relacionados à posição das peças do jogo Quoridor (Santos, \& Ortega, 2009):

(...) está no começo do jogo. É a vez do jogador vermelho. Quais estratégias ele poderia utilizar para começar? Por quê? (Santos, \& Ortega, 2009, p.37);

(...) é melhor avançar ou colocar as barreiras? (Santos, \& Ortega, 2009, p.37);

Porque andar com peão vermelho não é uma boa opção? (Santos, \& Ortega, 2009, p.37).

Ainda, no estudo de Sudo e cols. (2008), a pesquisadora fazia perguntas aos jogadores a fim de auxiliá-los a ler as palavras corretamente:

(...) quem sabe qual é a palavrinha do Joãozinho? Vocês lembram? Quem brincou com ela ontem? Que figura é essa? (Sudo, \& cols., 2008, p. 229).

O comportamento de resolver problemas, bem como a atenção, a observação e a discriminação dos estímulos relevantes para a resolução dos problemas são comportamentos operantes. Esse tipo de comportamento (resolução de um problema) geralmente está sob o controle de uma relação última de reforço e o processo de encontrar uma solução para o problema envolve a manipulação de variáveis, que aumentem a probabilidade da obtenção da solução (Skinner, 1953/1998; Baum, 2006). Assim, solucionar problemas envolve seguir instruções, emitir comportamentos que alteram os eventos do ambiente, discriminar os estímulos produzidos por essa modificação, alterar novamente o ambiente fazendo nova discriminação e, assim por diante, até que se obtenha como resultado a solução do problema que é o reforço. A descrição das contingências modificadas à medida que se manipula o ambiente produzindo estímulos discriminativos são consideradas instruções (autoinstruções), uma vez que se reconhece que falar consigo é um comportamento (Baum, 2006). Um exemplo de autoinstrução são as perguntas e as repostas feitas a si, a fim de estabelecer a resposta solução do problema. Esse comportamento é chamado de precorrente (também denominado de raciocínio, imaginação e formulação de hipóteses; Baum, 2006). Identificaram-se nos artigos revisados argumentos que indicam que o jogo é arranjado de forma a permitir que o jogador formule hipóteses.

Conforme as dicas são reveladas, os sujeitos levantam hipóteses acerca da regra de acentuação gráfica da palavra em foco (Cezar, \& cols., 2008, p. 69). 
(...) o jogo possibilita a tomada de decisões, o que ocorre nas casas Decisão Saudável. Antes de cair nessa casa, a criança já vislumbrou quais são os reais hábitos de saúde abordados, pois estes estão vinculados a prêmios ou penalidades. (Toscani, \& cols., 2007, p. 283).

O ambiente lúdico do jogo é um espaço privilegiado para a promoção da aprendizagem. Nele o participante enfrenta desafios, testa limites, soluciona problemas e formula hipóteses (Toscani, \& cols., 2007, p. 283).

Ainda são atribuídas aos jogos as características de permitir que as habilidades ensinadas por meio deles possam ser generalizadas para situações de estímulo novas ou em outras situações escolares ou fora da escola, conforme os argumentos listados a seguir.

(...) construção de competências que permitam articular tais esquemas com os próprios desafios do jogo e do cotidiano dos jogadores (Santos, \& Ortega, 2009, p. 47);

(...) a evolução na compreensão de jogo sugere um desenvolvimento que pode ser aplicado a outras situações da vida do sujeito (Santos, \& Ortega, 2009, p.46);

(...) construção de novas palavras, por meio da recombinação de unidades das palavras anteriormente aprendidas, leva à generalização de leitura (Sudo, \& cols., 2008, p. 234).

Esses argumentos apresentam de forma clara o processo de generalização de estímulos, que consiste em apresentar uma resposta semelhante na presença de estímulos novos que compartilham alguma propriedade física com o estímulo discriminativo (Catania, 1999; Gadelha, \& Vasconcelos, 2005). Esse conceito se refere à dispersão do efeito do reforço que ocorreu na presença de um estímulo para outros estímulos não correlacionados com o reforço. A generalização de estímulos pode ser reconhecida na medida em que os autores dos artigos revisados sugerem que uma resposta emitida em situação de jogo, na presença de determinados estímulos, pode ser emitida na presença de estímulos semelhantes em outra situação.

Ao utilizar jogos como recurso para auxiliar no ensino de conteúdos específicos, faz-se necessário especificar as dimensões dos estímulos que serão utilizados para que se favoreça a generalização de estímulos no dia a dia do jogador. Essas dimensões compreendem os tipos de estímulos que serão utilizados, o número de sessões de jogos que serão realizadas, o tipo de reforço que será empregado e as instruções (regras) que serão utilizadas nos jogos, para que se possam estabelecer condições para que a generalização de estímulos ocorra. A facilitação da generalização de estímulos deve constituir um dos objetivos dos jogos educativos, uma vez que dessa forma novas respostas são emitidas prontamente, não sendo necessária a modelagem da resposta a cada novo estímulo.
Ao se considerar a generalização de estímulos pode-se sugerir que os jogos educativos ampliam também o comportamento de atuar em situações simuladas e de brincadeira, por estabelecerem controle de estímulos generalizado e apropriado para esse tipo de situação. Assim, pode-se sugerir que o jogar é uma cunha comportamental (behavioral cups) (Rosales-Ruiz, \& Bear, 1997), tal como o brincar foi considerado por de Rose e Gil (2003). Cunhas comportamentais são classes mais gerais de comportamentos que dão acesso a uma variedade ampla de contingências como a exposição a ambientes novos e reforçadores que vão além das consequências idiossincráticas dos comportamentos (Rosales-Ruiz ,\& Bear, 1997). Jogar e brincar são comportamentos que podem ser oportunidades “(...) para modificar vários repertórios da criança cada um deles criando a possibilidade de acesso a novos ambientes, que irão, por sua vez, dar origem a novos comportamentos" (de Rose, \& Gil, 2003, p. 381)

\section{Considerações Finais}

Pesquisas com jogos educativos têm sido realizadas por profissionais das áreas de Humanas, da Saúde e da Biologia com o objetivo de avaliar esses instrumentos e ampliar a possibilidade de sua utilização como tecnologia educacional. Para identificar os argumentos que descrevem as características dos jogos atribuídas pelos autores de estudos empíricos da bibliografia dessas áreas, foram feitas buscas nas bases de dados Scielo e Pepsic, e realizou-se uma interpretação analítica comportamental dos argumentos selecionados.

A análise dos argumentos que especificam as características dos jogos atribuídas pelos autores possibilitou identificar os processos comportamentais envolvidos e as prováveis funções dos jogos. Reconheceu-se, assim, que os jogos educativos dos estudos da presente revisão apresentam funções motivadoras e a de estratégias de ensino. A função motivadora está relacionada ao estabelecimento de contingências de reforço e de operações estabelecedoras, enquanto a função de estratégia de ensino permite afirmar que os jogos promovem a aprendizagem por desenvolverem comportamento de solucionar problemas, o controle de estímulos e o controle instrucional. A função motivacional e o desenvolvimento desses repertórios comportamentais são importantes para a Educação e o desenvolvimento de aprendizes em qualquer faixa etária.

A identificação e a descrição das características dos jogos educativos feita pelos autores dos artigos desta revisão bibliográfica permitem considerar os jogos não apenas como um instrumento que proporciona a diversão, mas também como uma tecnologia capaz de facilitar e acelerar a aprendizagem, ou seja, facilitar mudanças de comportamento porque podem promover um rearranjo de contingências educacionais. O arranjo e rearranjo de contingências implica no planejamento das condições de ensino. A descrição dos 
princípios da Análise do Comportamento que fundamentam os jogos pode ser importante por permitir que o professor e/ ou psicólogo, conhecendo tais princípios, venha a usar os jogos em tarefas de ensino de maneira programada, isto é, com objetivos específicos, potencializando a aprendizagem acadêmica. Os jogos como recursos que auxiliam no arranjo das contingências para um ensino eficaz podem facilitar a emissão das respostas a serem aprendidas, bem como a manutenção e a generalização destas para diferentes contextos.

As contingências só podem ser arranjadas ou planejadas quando se tem clareza das mudanças comportamentais que se deseja promover. Contingências de ensino melhoradas e planejadas podem acelerar o processo de aprendizagem e podem gerar comportamento que de outro modo não apareceriam (Skinner, 1968/1972). O jogo pode ser utilizado como uma ferramenta para o ensino por meio do qual respostas corretas podem ser reforçadas, enquanto os erros ficariam reduzidos ao mínimo. Um ensino fundado em noções construídas a partir de uma análise científica do comportamento possibilita a utilização de critérios para o planejamento, execução e avaliação e, dessa forma, segundo Zanotto (2000), não requer que se procurem culpados pela ineficácia do trabalho educacional desenvolvido.

\section{Referências}

Baum, W. M. (2006). Compreender o Behaviorismo: comportamento, cultura e evolução. Porto Alegre: ArtMed.

Canto, A. R., \& Zacarias, M. A. (2009). Utilização do jogo Super Trunfo Árvores Brasileiras como instrumento facilitador no ensino dos biomas brasileiros. Ciência e Cognição, 14, 144-153.

Catania, A. C. (1999). Aprendizagem: comportamento, linguagem e cognição. (D. G. de Souza, Trad.) (4 ${ }^{\mathrm{a}}$ ed.). Porto Alegre: ArtMed. (Publicado originalmente em 1998).

Caminha, R. M., \& Caminha, M. G. (2010). Baralho das emoções. ( $3^{\mathrm{a}}$ ed.) Novo Hamburgo, RS: Sinopsys.

Cezar, K. P. L., Morais, N. C. B., Calsa, G. C., \& Romualdo, E. C. (2008). Acentuação gráfica: criação e aplicação de um jogo de regras. Revista de Psicopedagogia, 25, 62-74.

Dondi, C., \& Moretti, M. (2007). A methodological proposal for learning games selection and quality assessment. British Journal of Educational Technology, 38, 502- 512.

Ferreira, A. C. M, Gris, G., Oliveira, G. T., Alves, H. W, Haydu, V. B, Costa, C. E, \& Souza, S. S. (2013). O uso de jogos como instrumentos para o ensino de princípios/conceitos de análise experimental do comportamento. Em V. B. Haydu, \& S. R. Souza (Orgs.), Psicologia comportamental aplicada: avaliação e intervenção nas áreas da saúde, da clínica, da educação e do esporte (Vol. 2, pp. 269-293) Londrina, PR: EDUEL.
Fonseca, L. M. M., Scochi, C. G. S., \& Mello, D. F. (2002). Educação em saúde de puérperas em alojamento neonatal: aquisição de conhecimento mediado pelo uso de um jogo educativo. Revista Latino Americana de Enfermagem, 10, 166-171.

Gadelha, Y. A., \& Vasconcelos, L. A. (2005). Generalização de estímulos: aspectos conceituais, metodológicos e de intervenção. Em J. Abreu-Rodrigues, \& M. M. Ribeiro (Orgs.), Análise do comportamento: pesquisa, teoria e aplicação (pp. 141-160). Porto Alegre: Artmed.

Haydu, V. B. (2014). O modelo da equivalência de estímulos na forma de jogos educativos para o ensino leitura e escrita em contexto coletivo. Em V. B. Haydu, S. A. Fornazari, \& C. R. Estanislau (Orgs.), Psicologia e análise do comportamento: conceituações e aplicações à educação, organizações, saúde e clínica (pp. 177197). Londrina: Universidade Estadual de Londrina.

Matos, M. A. (1993). Análise de contingências no aprender e no ensinar. Em E. S. Alencar (Org.), Novas contribuições da psicologia nos processos de ensino e aprendizagem. São Paulo: Cortez.

Michael, J. (2004). Concepts and principles of behavior analysis $\left(2^{\mathrm{a}}\right.$ ed.). Kalamazoo, MI: Association for Behavior Analysis.

Moreira, M. B., \& Medeiros, C. A. (2007). Princípios básicos de análise do comportamento. Porto Alegre: ArtMed.

Moura, C. B. (2006). Será que conheço você? Versão para 10 a 14 anos. Terapia Criativa. Recuperado: 14 de set. 2012. Disponível: http://www.terapiacriativa.com.br/produtos.asp?produto=169.

Rosales-Ruiz, \& Bear, D. M. (1997). Behavioral Cusps: a developmental and pragmatic concept for behavior analysis. Journal of Applied Behavior Analysis, 30, 533-544.

Rose, J. C. C., \& Gil, M. S. C (2003). Para uma análise do brincar e de sua função educacional - a função educacional do brincar. Em M. Z. S. Brandão, \& cols. (Orgs.), Sobre comportamento e cognição: a história e os avanços, a seleção por consequências em ação (Vol. 11, pp. 373-382). Santo André: ESETec.

Santos, C. C., \& Ortega, A. C. (2009). O jogo de regras como recurso para avaliação e intervenção: um estudo piagetiano com adolescentes. Ciência e Cognição, 14, 26-49.

Schlinger, H. D. (1993). Separating discriminative and functionaltering effects of verbal stimuli. The Behavior Analyst, 16, 9-23.

Sdoukos, S. S., Pellizzetti, G. B. F. R., Ruas, T. V., Xander, P., Souza, S. R., \& Haydu, V. B. (2010). Desenvolvimento de um jogo de tabuleiro para o ensino de manejo de dinheiro com base em relações de estímulos equivalentes [Resumo]. Resumos de Comunicação Científica, XL Reunião Anual da Sociedade Brasileira de Psicologia (p. 1), Curitiba: SBP. 
Siqueira, E. S., Barros, S. E, \& Marques, B. L., \& Monteiro, C. D (2011). Um jogo com reconhecedor de voz para o ensino de crianças com dificuldade de aprendizagem em leitura e escrita. Em Sociedade Brasileira de Computação (Org.), XXXI Congresso da Sociedade Brasileira de Computação, Anais CSBC 2011 (pp. 1279-1292), Natal: SBC. Recuperado: 26 jun. 2013. Disponível: http://www. dimap.ufrn.br/csbc2011/anais/eventos/contents/CADERNO.pdf.

Skinner, B. F. (1972). Tecnologia do ensino (R. Azzi, Trad.). São Paulo: E.P.U (Trabalho original publicado em 1968).

Skinner, B. F. (1980). Contingências do reforço: Uma análise teórica (R. Moreno, Trad.). Coleção Os Pensadores. São Paulo: Abril Cultural. (Trabalho original publicado em 1969).

Skinner, B. F. (1998). Ciência e comportamento humano. São Paulo: Martins Fontes. (Trabalho original publicado em 1953).

Schlinger, H. D., \& Blakely, E. (1987). Function-altering effects of contingency-specifying stimuli. The Behavior Analyst, 10, 41-45.

Souza, S. R., \& Hübner, M. M. C. (2010). Efeitos de um jogo de tabuleiro educativo na aquisição de leitura e escrita. Acta Comportamentalia, 18, 215-242.
Sudo, C. H., Soares, P. G., Souza, S. R., \& Haydu, V. B. (2008). Equivalência de estímulos e uso de jogos para ensinar leitura e escrita. Revista Brasileira de Terapia Comportamental e Cognitiva, 10, 223-238.

Sundberg, M. L. (2013). Thirty points about motivation from Skinner's book Verbal Behavior. The Analysis of Verbal Behavior, 29, 13-40.

Toscani, N. V., Santos, A. J. D. S., Silva, L. L. M., Tonial, C. T., Chazan, M., Wiebbelling, A. M. P., \& Mezzari, A. (2007). Desenvolvimento e análise de jogo educativo para crianças visando à prevenção de doenças parasitológicas. Interface - Comunicação, Saúde e Educação, 11, 281-294.

Varga, J. S. (2013). Behavior analysis for effective teaching ( $2^{\mathrm{a}}$ ed.). New York: Routledge/Taylor and Francis.

Xander, P (2013). "Dimdim: negociando \& brincando" no ensino de habilidades monetárias a pré-escolares. Dissertação de Mestrado não publicada, Mestrado em Análise do Comportamento, Universidade Estadual de Londrina, Londrina, Paraná, Brasil.

Zanotto, M. L. B. (2000). Formação de professores a contribuição da análise do comportamento. São Paulo: EDUC.

\section{Sobre as autoras:}

Mariana Gomide Panosso (mariana_panosso@hotmail.com)

Mestre em Análise do Comportamento pelo Programa de Pós-graduação em Análise do Comportamento da Universidade Estadual de Londrina. Doutoranda na Universidade Federal de São Carlos.

Silvia Regina de Souza (ssouza@uel.br)

Professora Associada do Departamento de Psicologia Geral e Análise do

Comportamento da Universidade Estadual de Londrina e do Programa de Mestrado em Análise do Comportamento. Doutora em Psicologia Clínica pela USP.

\section{Verônica Bender Haydu}

Professora Adjunto do Departamento de Psicologia Geral e Análise do Comportamento da Universidade Estadual de Londrina e do Programa de Mestrado em Análise do Comportamento. Doutora em Psicologia Experimental pela USP. 
